\title{
Relationship between Work Ability Index and Cognitive Failure among Nurses
}

Milad Abbasi ${ }^{1,2}$, Abolfazl Zakerian ${ }^{3}$, Malihe Kolahdouzi ${ }^{4}$, Ahmad Mehri ${ }^{5}$, Arash Akbarzadeh ${ }^{6}$, Mohammad Hossein Ebrahimi ${ }^{7}$

${ }^{1}$ Research Center for Environmental Determinants of Health (RCEDH), Kermanshah University of Medical Sciences, Kermanshah, Iran

${ }^{2}$ M.Sc. of Occupational Health Engineering, Department of Occupational Health Engineering, School of Public Health, Tehran University of Medical Sciences, Tehran, Iran

${ }^{3} \mathrm{Ph}$.D. of Occupational Health Engineering, Associate Professor, Department of Occupational Health Engineering, School of Public Health, Tehran University of Medical Sciences, Tehran, Iran

${ }^{4}$ M.Sc. of Occupational Health Engineering, Department of Occupational Health Engineering, School of Public Health, Sahahid Sadoughi University of Medical Sciences, Yazd, Iran

${ }^{5}$ M.Sc. of Occupational Health Engineering, Department of Occupational Health Engineering, School of Public Health, Ilam University of Medical Sciences, Ilam, Iran

${ }^{6}$ M.Sc. of Biostatistics, Department of Biostatistics and Epidemiology, School of Public Health, Tehran University of Medical Sciences, Tehran, Iran

${ }^{7}$ M.D, Assistant Professor of Occupational Medicine, Department of Occupational Health Engineering, Occupational and Environmental Health Research Center, Shahroud University of Medical Sciences, Shahroud, Iran

\section{Type of article: Original}

\begin{abstract}
Introduction: Frequent nursing errors are considered as factors that affect the quality of healthcare of patients. Capable nurses who are compatible with work conditions are more focused on their tasks, and this reduces their errors and cognitive failures. Therefore, this study was conducted with the aim of investigating the relationship between work ability index (WAI) and cognitive failures (CFs) as well as some factors that affect them in nurses working in the ICU, CCU, and emergency wards.

Methods: This descriptive-analytical and cross-sectional study was conducted with 750 nurses at educational hospitals affiliated with the Tehran University of Medical Sciences in 2015. A questionnaire of work ability index and cognitive failures was used to collect data. The data were analyzed using SPSS 20 and the Pearson and Spearman correlation coefficients, chi-squared, ANOVA, and the Kruskal-Wallis tests.

Results: Using the Pearson correlation test, the results of this study showed that there is a significant, inverse relationship between WAI, personal prognosis of work ability, and mental resources with CFs along with all its subscales in nurses $(\mathrm{p}<0.05)$. In addition, there was an inverse and significant relationship between the total score of CFs and the estimated work impairment due to diseases $(p<0.05)$. There was a significant positive correlation of CFs with age and experience, while WAI was inversely related to age, work experience, and body mass index (BMI) $(p<0.05)$. WAI and CFs were related significantly to working units $(p<0.05)$.

Conclusion: Considering the results obtained in this study, WAI and the cognitive status of nurses were lower than the specified limit. It is suggested that the work ability of nurses be improved and that their CFs be reduced through various measures, including pre-employment examinations, proper management of work-shift conditions, and using engineering and administrative strategies to ensure the safety of hospitalized patients.
\end{abstract}

Keywords: cognitive failure; nurse; work ability index

\section{Corresponding author:}

Assistant Professor Dr. Mohammad Hossein Ebrahimi, Department of Occupational Health Engineering, Occupational and Environmental Health Research Center, Shahroud University of Medical Sciences, Shahroud, Iran. Tel: +98.9189928285, E-mail: Ebrahimi_Mh@hotmail.com

Received: October 03, 2015, Accepted: December 25, 2015, Published: March 2016

iThenticate screening: December 18, 2015, English editing: February 12, 2016, Quality control: March 08, 2016

(C) 2016 The Authors. This is an open access article under the terms of the Creative Commons Attribution-NonCommercialNoDerivs License, which permits use and distribution in any medium, provided the original work is properly cited, the use is non-commercial and no modifications or adaptations are made. 


\section{Introduction}

Nurses are regarded as an integral part of the healthcare system (1), but, among them, psychological problems and occupational stress are very common $(2,3)$. The poor mental health of nurses imposes unfavorable effects on them and on the safety of patients under their care $(4,5)$. Nurses make errors and mistakes in providing care irrespective of how skillful, committed, and accurate they may be (6). The findings of studies of nurses' errors identified several issues, including the universality and inevitability of errors, multifactor errors, and the need to have a systematic approach rather than a personal approach in dealing with errors (7). Night work, long shifts, and the unpredictability of their activities increase the possibility of their becoming fatigued, and this can reduce their physical performance and capacity, thereby increasing the possibility of work errors (8). Annually, nursing errors contribute to the deaths of thousands of people, harm to many others, and increased expenditures for treatment (9). The outcomes of these errors are prolonged hospitalization, increased expenditures for treatment, and, in some cases, severe harm to patients, even including death (10). Cognitive failures (CFs) are defined as mental-dependent errors in tasks that could be seamless and fully done by a person. These errors and failures include problems that result from flawed memory, perceptions, and functions. Evidence shows that there is a significant correlation between accidents and cognitive failures $(11,12)$. Furthermore, there is a relationship between accidents and distractibility, poor selective attention, and mental errors $(13,14)$. Cognitive failures are related directly to occupational stressors, and occupational stress is rooted in one's inability to perform her or his duties (15). Therefore, it could be stated that cognitive failures are the indirect result of the inability of nurses to do their tasks. Occupational stress that occurs due to mismatch of individuals' ability and their job requirements could increase the frequency of errors and failures (16). According to occupational health studies, the concept of work ability is based on an appropriate balance between the features and capabilities of the individuals and the demands of their jobs $(17,18)$. Work ability could be defined as an index that shows how well a person is able to do her or his job in the best way considering job demands, health status, and intellectual-mental capabilities (19). Various factors, including age, unhealthy lifestyles, poor physical health, various diseases, and high or low BMI have negative effects on the work ability of people (13, 14). In addition, the work ability of employees is an index of their job satisfaction and an important factor in their occupational quality and job security (20) in such a way that proper performance of tasks because of high work ability would increase job satisfaction, and high job satisfaction is a factor that provides the background for decreasing cognitive failures (21). Due to high population of Tehran, the importance of the quality of healthcare, and the lack of nurses, it is very important to consider the role of nurses as a main component of the health system (22). However, because of many limitations of nurses' jobs, there is a growing trend toward rapid turnover. Thus, it is essential to pay attention to nursing and nurses' job challenges to reduce irreparable losses and increase the quality of healthcare (22). This is essential there are many problems in this field that must be dealt with, including low job status, low job satisfaction, low motivation, and protecting patients' welfare from nursing errors. Thus, this study was conducted to investigate the relationship between work ability index, cognitive failures, and the factors that affect these two important components among nurses who work in the emergency ward, the ICU, and the CCU in the educational hospitals affiliated with the Tehran University of Medical Sciences.

\section{Material and Methods}

Due to the vital importance of the emergency ward, the ICU, and the CCU in maintaining and improving patients' health, as well as the importance of the unpleasant consequences of errors in these areas in which nurses need high work ability and capacity, we investigated the nurses working in these wards in the educational hospitals affiliated with the Tehran University of Medical Sciences. This cross-sectional and descriptive-analytic study was conducted in 2015, and it included 750 nurses who were working in these hospitals. The tools used to collect data were a general questionnaire to measure background and demographic variables and two specialized and standardized questionnaires of WAI and cognitive failures that were used to measure work ability and the amount of cognitive failures, respectively. A brief explanation of this questionnaire is provided below:

1) Work Ability Index Questionnaire:

This tool was developed to assess the work ability of people in their work environments. This questionnaire consisted of seven items, i.e., 1) current work ability compared with the lifetime best, 2) work ability in relation to work demands (physical or mental), 3) current diseases diagnosed by a physician, 4) estimated work impairment due to these diseases, 5) sick leave during the past 12 months, and 7) personal prognosis of work ability two years from now as well as mental resources, each of which was evaluated using one or more questions. This index was calculated by the sum of scores obtained for each item. The best estimation was related to WAI with the score of 49, and the worst estimation was related to score 7. The validity and reliability of the Persian version of this questionnaire was examined by Arastoo et al., and a Cronbach's alpha value of 0.78 was obtained (23).

2) Cognitive Failures Questionnaire (CFQ): 
Broadbent's cognitive failures questionnaire consists of 25 questions that address the four aspects of failure in memory, memory for names, perception, and motor function (16). This questionnaire considers different aspects of cognition, cognitive features, and various theories of cognitive failures as well as subscales and layers where cognitive failures occur. In a study conducted by Allahyari et al., the internal consistency and reproducibility of this tool were examined to determine its reliability. The results obtained from this study showed that the value of Cronbach's alpha of the Persian questionnaire of cognitive failures was 0.96, which indicated the high reliability of this measurement tool (24). The scores on the CFQ ranged from zero to 100, and a higher score implies more failures.

\section{Results}

\subsection{General Findings}

In this study, 750 nurses participated, including 460 females (61.4\%) and 290 males (38.6\%). Of them, 343 (45.7\%), $214(28.6 \%)$, and 193 (25.7\%) nurses were working at ICU, CCU, and the emergency ward, respectively. According to results of this study, mean age (standard deviation), employment history, and BMI were obtained to be 33.1 (8.0), 10.2 (7.6) and 24.2 (3.0), respectively. The subjects worked 22.5 work shifts per month on average, and 6.2 patients were under their care per shift. With regard to work ability index, the average work ability index (standard deviation) for all participants was obtained to be 36.92 (4.46). According to the nurses, current work ability and mental resources were the most and the least important aspects of work ability, respectively. In addition, work ability in the CCU and emergency ward accounted for the highest and lowest value, respectively. The mean and standard deviation of work ability index and its subscales are generally and separately shown in Table 1 . In relation with cognitive failures, mean (standard deviation) of general score of cognitive failures was 40.55 (12.71) for all participants. According to the nurses, perception and memory for names were the most and least important subscales of cognitive failures, respectively. In addition, general cognitive failures in emergency and CCU ward accounted for the most and least values, respectively. The mean and standard deviation of general cognitive failures and its subscales, including memory, memory for names, perception, and motor function, are shown in Table 2 for each ward.

Table 1. Mean (SD) work ability index and its subscales in separation of the working unit

\begin{tabular}{|l|l|l|l|l|}
\hline WAI subscales & $\begin{array}{l}\text { WAI and its subscales } \\
\text { in all individuals } \\
\text { [Mean (SD) }\end{array}$ & \multicolumn{2}{|l|}{ Working units } \\
\cline { 3 - 5 } & Emergency & ICU & CCU \\
\hline $\begin{array}{l}\text { Current work ability compared with the } \\
\text { lifetime best }\end{array}$ & $7.75(1.34)$ & $8.27(1.18)$ & $7.59(1.27)$ & $7.55(1.48)$ \\
\hline $\begin{array}{l}\text { Work ability in relation to the demands of } \\
\text { the job }\end{array}$ & $7.7(1.32)$ & $7.69(1.73)$ & $7.81(1.11)$ & $7.52(1.21)$ \\
\hline Current diseases diagnosed by a physician & $4.43(2.2)$ & $4.00(2.16)$ & $4.29(2.1)$ & $4.72(2.3)$ \\
\hline Estimated work impairment due to diseases & $5.47(0.77)$ & $5.38(0.76)$ & $5.45(0.79)$ & $5.6(0.74)$ \\
\hline Sick leave during the past 12 months & $4.05(0.98)$ & $3.38(1.04)$ & $4.07(0.91)$ & $4.62(0.58)$ \\
\hline $\begin{array}{l}\text { Personal prognosis of work ability 2 years } \\
\text { from now }\end{array}$ & $4.72(2.3)$ & $3.75(2.52)$ & $4.42(2.13)$ & $6.1(1.69)$ \\
\hline Mental resources & $2.85(0.75)$ & $2.61(0.93)$ & $2.98(0.7)$ & $2.87(0.61)$ \\
\hline
\end{tabular}

Table 2. Mean (SD) cognitive failure and its subscales in separation of the working unit

\begin{tabular}{|c|c|c|c|c|c|c|}
\hline \multicolumn{2}{|l|}{ CFs subscales } & Memory & $\begin{array}{l}\text { Memory for } \\
\text { names }\end{array}$ & Perception & $\begin{array}{l}\text { Motor } \\
\text { function }\end{array}$ & $\begin{array}{l}\text { Total score of } \\
\text { CFs }\end{array}$ \\
\hline \multicolumn{2}{|c|}{$\begin{array}{l}\text { CFs and its subscales in all } \\
\text { individuals }\end{array}$} & $11.95(4.83)$ & $3.57(1.53)$ & $15.67(5.38)$ & $11.02(3.6)$ & $40.55(12.71)$ \\
\hline \multirow[t]{3}{*}{ Working units } & Emergency & $14.22(4.06)$ & $4.25(1.38)$ & $18.75(4.14)$ & $13.28(2.8)$ & $48.44(10.4)$ \\
\hline & ICU & $12.34(4.89)$ & $3.56(1.52)$ & $15.73(4.72)$ & $10.68(3.39)$ & $40.67(11.31)$ \\
\hline & $\mathrm{CCU}$ & $9.27(4.19)$ & $3.00(1.46)$ & $12.82(5.91)$ & $9.52(3.88)$ & $33.27(12.35)$ \\
\hline
\end{tabular}

\subsection{Relationship between Work Ability and Cognitive Failures}

Relation of subscales of WAI and cognitive failures was investigated using the Pearson correlation test. According to the results obtained at a confidence level of $95 \%$, there was an inverse and significant relationship between total 
score of WAI and total score of cognitive failures and all its subscales in nurses $(\mathrm{p}<0.05)$. In addition, there was an inverse and significant relationship between total score of cognitive failures and estimated work impairment due to diseases, prognosis of work ability, and mental resources $(p<0.05)$. The relation of WAI and cognitive failures, along with their subscales, are shown in Table 3.

Table 3. Relationship between work ability index and cognitive failure and its dimensions

\begin{tabular}{|c|c|c|c|c|c|}
\hline \multirow[t]{2}{*}{ WAI } & \multicolumn{5}{|c|}{ CF [Pearson correlation (p-value)] } \\
\hline & $\begin{array}{l}\text { Total score } \\
\text { of CFs }\end{array}$ & $\begin{array}{l}\text { Motor } \\
\text { function }\end{array}$ & Perception & $\begin{array}{l}\text { Memory for } \\
\text { names }\end{array}$ & Memory \\
\hline $\begin{array}{l}\text { Current work ability compared with the } \\
\text { lifetime best }\end{array}$ & $0.16(0.06)$ & $-0.17(0.05)$ & $0.1(0.22)$ & $0.12(0.15)$ & $\begin{array}{l}0.18^{*} \\
(0.03)\end{array}$ \\
\hline $\begin{array}{l}\text { Work ability in relation to the demands } \\
\text { of the job }\end{array}$ & $-0.07(0.39)$ & $-0.04(0.67)$ & $-0.06(0.47)$ & $0.001(0.9)$ & $-0.11(0.21)$ \\
\hline $\begin{array}{l}\text { current diseases diagnosed by a } \\
\text { physician }\end{array}$ & $-0.16(0.05)$ & $-0.13(0.11)$ & $-0.16(0.05)$ & $\begin{array}{l}-0.18^{*} \\
(0.03)\end{array}$ & $\begin{array}{l}-0.18^{*} \\
(0.03)\end{array}$ \\
\hline $\begin{array}{l}\text { Estimated work impairment due to } \\
\text { diseases }\end{array}$ & $\begin{array}{l}-0.18^{*} \\
(0.03)\end{array}$ & $-0.16(0.06)$ & $-0.13(0.11)$ & $-0.07(0.39)$ & $\begin{array}{l}-0.26^{*} \\
(0.001)\end{array}$ \\
\hline Sick leave during the past 12 months & $-0.13(0.11)$ & $-0.08(0.34)$ & $-0.14(0.08)$ & $-0.08(0.37)$ & $\begin{array}{l}0.18^{*} \\
(0.03)\end{array}$ \\
\hline $\begin{array}{l}\text { Personal prognosis of work ability } 2 \\
\text { years from now }\end{array}$ & $\begin{array}{l}-0.35^{*} \\
(0.001)\end{array}$ & $\begin{array}{l}-0.29^{*} \\
(0.001)\end{array}$ & $\begin{array}{l}-0.33^{*} \\
(0.001)\end{array}$ & $\begin{array}{l}-0.22 * \\
(0.01)\end{array}$ & $\begin{array}{l}-0.37^{*} \\
(0.001)\end{array}$ \\
\hline Mental resources & $\begin{array}{l}-0.24 * \\
(0.001)\end{array}$ & $\begin{array}{l}-0.22 * \\
(0.001)\end{array}$ & $\begin{array}{l}-0.21 * \\
(0.01)\end{array}$ & $\begin{array}{l}-0.21 * \\
(0.01)\end{array}$ & $-0.25(089)$ \\
\hline Total score of WAI & $\begin{array}{l}-0.34 * \\
(0.001)\end{array}$ & $\begin{array}{l}-0.22 * \\
(0.001)\end{array}$ & $\begin{array}{l}-0.31^{*} \\
(0.001)\end{array}$ & $\begin{array}{l}-0.21^{*} \\
(0.01)\end{array}$ & $\begin{array}{l}-0.36^{*} \\
(0.001)\end{array}$ \\
\hline
\end{tabular}

* Significant at a confidence level of $95 \%$

\subsection{Relationship between WAI and its Subscales with background and demographic Variables}

After classifying variables, results of Spearman and Pearson test showed that WAI and its subscales (except work ability related to work demands and estimated work impairment due to diseases) were inversely and significantly related to age $(\mathrm{p}<0.05)$. In addition, current work ability was positively related to work experience; current diseases were positively related to BMI and inversely related to work experience. Estimated work impairment due to diseases was inversely and significantly related to BMI $(\mathrm{p}<0.05)$. Sick leave during the past 12 months was inversely and significantly related to work experience and number of patients under care $(\mathrm{p}<0.05)$. Prognosis of work ability and mental resources were inversely and significantly related to work experience, and total score of WAI was inversely and significantly related to age, BMI, and work experience of the nurses $(\mathrm{p}<0.05)$. The results are shown in Table 4. Furthermore, the results of ANOVA and the Kruskal-Wallis test showed that there was a significant relationship between work ability index, age groups, and work experience. The results of ANOVA showed that WAI was significantly related to different working wards $(\mathrm{p}<0.05)$. To investigate the relation between gender and WAI, the chi-squared test was used after classification of WAI, and the results showed that there was no significant relationship between work ability index and gender $(\mathrm{p}<0.05)$.

\subsection{Relationship between Cognitive Failures and its Subscales with background and demographic Variables}

To investigate the relation between classified background variables and subscales of cognitive failures, the Spearman and Pearson correlation tests were used. Based on these tests (Table 5), there was a significant positive relationship between memory, memory for names, perception, and motor function and total score of cognitive failure of nurses with age and work experience $(\mathrm{p}<0.05)$. In addition, there was a positive relation between memory for names and BMI and an inverse and significant relation with number of patients under care in any shift $(\mathrm{p}<0.05)$. Furthermore, the results of ANOVA and the Kruskal-Wallis test showed that there is a significant relationship between WAI and cognitive failures with age and work experience. Results of ANOVA showed that there is a significant relationship between cognitive failures and different working wards $(\mathrm{p}<0.05)$. In addition, to investigate the relation between gender and classified cognitive failures, the chi-squared test was used, and the results showed that there was no significant relationship between cognitive failures and gender $(\mathrm{p}<0.05)$. 
Table 4. Relation between demographic and background variables with work ability index and its subscales

\begin{tabular}{|l|l|l|l|l|l|}
\hline \multirow{2}{*}{ WAI } & \multicolumn{3}{|l|}{ Background variables [Pearson and Spearman correlation (p-value) ] } \\
\cline { 2 - 6 } & Age & $\begin{array}{l}\text { Body mass } \\
\text { index }\end{array}$ & Experience & $\begin{array}{l}\text { Number } \\
\text { of shifts }\end{array}$ & $\begin{array}{l}\text { Number of patients } \\
\text { under supervision }\end{array}$ \\
\hline $\begin{array}{l}\text { Current work ability compared } \\
\text { with the lifetime best }\end{array}$ & $0.15(0.0 .6)$ & $-0.03(0.7)$ & $\begin{array}{l}0.18^{*} \\
(0.03)\end{array}$ & $\begin{array}{l}0.09 \\
(0.28)\end{array}$ & $-0.1(0.23)$ \\
\hline $\begin{array}{l}\text { Work ability in relation to the } \\
\text { demands of the job }\end{array}$ & $0.04(0.57)$ & $\begin{array}{l}-0.004 \\
(0.96)\end{array}$ & $0.04(0.59)$ & $\begin{array}{l}0.05 \\
(0.53)\end{array}$ & $0.49(0.56)$ \\
\hline $\begin{array}{l}\text { current diseases diagnosed by a } \\
\text { physician }\end{array}$ & $\begin{array}{l}-0.19^{*} \\
(0.02)\end{array}$ & $\begin{array}{l}0.22^{*} \\
(0.01)\end{array}$ & $\begin{array}{l}-0.23^{*} \\
(0.001)\end{array}$ & $\begin{array}{l}0.05 \\
(0.53)\end{array}$ & $-0.12(0.17)$ \\
\hline $\begin{array}{l}\text { Estimated work impairment due to } \\
\text { diseases }\end{array}$ & $-0.15(0.07)$ & $-0.31^{*}$ & -0.14 & $0.1(0.24)$ & $-0.06(0.47)$ \\
\hline $\begin{array}{l}\text { Sick leave during the past 12 } \\
\text { months }\end{array}$ & $\begin{array}{l}-0.36^{*} \\
(0.001)\end{array}$ & $0.07(0.38)$ & $\begin{array}{l}-0.34^{*} \\
(0.001)\end{array}$ & $0.1(0.24)$ & $-0.23(0.001)$ \\
\hline $\begin{array}{l}\text { Personal prognosis of work ability } \\
\text { 2 years from now }\end{array}$ & $\begin{array}{l}-0.29^{*} \\
(0.001)\end{array}$ & $-0.02(0.8)$ & $\begin{array}{l}-0.28^{*} \\
(0.011)\end{array}$ & $0.1(0.24)$ & $0.03(0.69)$ \\
\hline Mental resources & $0.2^{*}(0.01)$ & $0.08(0.34)$ & $\begin{array}{l}-0.19^{*} \\
(0.02)\end{array}$ & $0.1(0.24)$ & $-0.01(0.86)$ \\
\hline Total score of WAI & $-0.33^{*}$ & $-0.18^{*}$ & $\begin{array}{l}-0.32^{*} \\
(0.001)\end{array}$ & $0.09(0.29)$ & $-0.11(0.19)$ \\
\hline
\end{tabular}

* Significant at a confidence level of $95 \%$

Table 5. Relation between demographic and background variables with CFs and its subscales

\begin{tabular}{|l|l|l|l|l|l|}
\hline \multirow{2}{*}{ CFs } & \multicolumn{4}{|l|}{ Background variables [Pearson and Spearman correlation (p-value)] } \\
\cline { 2 - 6 } & Age & $\begin{array}{l}\text { Body mass } \\
\text { index }\end{array}$ & Experience & $\begin{array}{l}\text { Number of } \\
\text { shifts }\end{array}$ & $\begin{array}{l}\text { Number of patients } \\
\text { under supervision }\end{array}$ \\
\hline Memory & $0.38^{*}(0.001)$ & $0.13(0.12)$ & $0.37^{*}(0.001)$ & $0.09(0.28)$ & $-0.003(0.96)$ \\
\hline Memory for names & $0.35^{*}(0.001)$ & $0.19(0.02)$ & $0.33^{*}(0.001)$ & $0.05(0.54)$ & $-0.17(0.04)$ \\
\hline Perception & $0.39^{*}(0.001)$ & $0.08(0.33)$ & $0.38^{*}(0.001)$ & $0.05(0.53)$ & $0.07(0.38)$ \\
\hline Motor function & $0.41^{*}(0.001)$ & $0.07(0.38)$ & $0.39^{*}(0.001)$ & $0.1(0.24)$ & $-0.009(0.92)$ \\
\hline Total score of CFs & $0.046^{*}(0.001)$ & $0.12(0.14)$ & $0.47^{*}(0.001)$ & $0.09(0.29)$ & $0.007(0.93)$ \\
\hline
\end{tabular}

* Significant at a confidence level of $95 \%$

\section{Discussion}

\subsection{Relation of WAI with Cognitive Failures and their Dimension}

Table 2 shows that total average of WAI was 36.9 for all subjects, and, since WAI of lower than 37 is regarded as poor work ability, it could be said that work ability of nurses is low in these wards. Therefore, to prevent problems resulting from poor work ability and to avoid early job turnover of subjects working in these wards, special attention should be paid to administrative and engineering interventions. Mental resources or psychological dimension of life had the lowest value for all wards because of the significant effect of psychological dimension on work ability. In a study by Stenfors et al., the positive relationship between high job requirements and cognitive failures was pointed out. Lack of attention could increase quantitative job demands and disrupt the process of removal of job demands of nurses and finally create negative changes in the work ability of nurses (25). Based on the results of Ilmarinen's study, the less ability the person doing the work has, the more cognitive failures and events there will be. Therefore, we can increase the work ability of nurses by creating conditions to decrease their cognitive failures and reduce concern about the early turnover of employees, which is one of the problems in the contemporary world (26). Cognitive failures were inversely and significantly related to three subscales of estimated work impairment, i.e., diseases, prognosis of work ability, and mental resources. These subscales were generally attributed to the mental and psychological dimensions of nurses (27). According to a previous study that dealt with the relationship between cognitive resources and mental state, the more the person is in psychologically-favorable conditions, the greater the occurrence of cognitive failures becomes. Therefore, the psychological dimension of nurses should be specifically considered (28). With regard to the findings of this study and Van den Burg et al.'s study, in which it was stated that the effect of psychological factors on WAI was higher compared to lifestyle (physical), we concluded that there is a 
special relationship and interaction between work ability of nurses and their cognitive status (28). In addition, poor work ability of nurses in the emergency ward was the result of their high workloads, since in the study by Salavati et al., the high workload in the emergency ward was pointed out (29). Rotenburg mentioned a significant relationship between workload and insufficient work ability as well. Therefore, by decreasing workload through increasing the number of nurses in the emergency ward or reducing the duration of work shifts, their work ability can be increased (30). With regard to the relation between current work ability and cognitive failures in the CCU, by providing proper conditions for nurses, including consideration and sufficient supervision of managers to optimize work environment in terms of interpersonal relations, the amount of workload and legal status of nurses, the background will be provided to promote current work ability and reduce the amount of cognitive failures (31).

\subsection{Relation of WAI and Cognitive Failures and Their Subscales with Background and Demographic Variables} Due to high workload and job stress in the emergency ward, the mental resources of nurses were decreased in this ward, and this affected their memory and perception, thereby resulting in increased cognitive failures. In the CCU, there was an inverse and significant relationship between work ability and the demands of the job. The more physical and mental ability a person has in relation to job demands, the less the amount of cognitive failures, especially cognitive failure of memory. In addition, according to a study by Lund et al., the high and low BMI results in long sick leave and inability and study by Martinez that stated the strong relationship between physical health and work ability, the relationship between WAI and BMI could be justified $(32,33)$. The inverse relation of WAI with age and work experience was identified in a study by Camerino et al. (34). The less work experience nurses have and the older they are, the greater the number of diagnosed diseases and disorders become, including musculoskeletal, cardiovascular, respiratory, nervous, gastrointestinal, endocrine, blood and skin diseases, as well as harm that results from events that occur (34). Every nurse bears more physical and mental workload according to overtime work hours in each month and the number of patients under their care in every work shift. In some cases, overtime work is after long work shifts, resulting in physical and mental effects as well as chronic and persistent fatigue in nurses. To resolve these disorders, nurses should use sick leave that shows reduced work ability of person during work hours. In this regard, Martinez et al. stated that nurses with more absences have lower work ability than others $(33,35)$. Because of the reproducibility of the work process, aging during work hours, increase in concerns related to social and family issues, and fading out the importance of job demands, the amount of cognitive failures and errors increase as time passes and as a result of which work events increase as well. As the number of patients under supervision increases in each work shift, fatigue increases as well, and people experience more cognitive failures. In this regard, it could be stated that by increasing the ratio of nurses to patients, a good measure is obtained to decrease the amount of cognitive failures of nurses.

\section{Conclusions}

The results of this study indicated that there is a significant relationship between WAI and cognitive failures of nurses working in the CCU, ICU, and emergency ward, in such a way that decreases in the nurses' work ability result in increases in their cognitive failures. Therefore, steps should be taken to reduce the amount of cognitive failures by accurate evaluation of work ability of those who apply to work in these wards and matching them with required work demands. It is suggested that hospital administrators reduce the losses that result from nursing errors in these wards by improving working conditions, proper management of work shifts, material and moral support as well as supplying nurses' demands to provide the background of reducing errors. Conducting a complementary prospective research could be a good path for later studies of this topic to investigate the effect of other variables on the amount of CFs of nurses working in all wards.

\section{Acknowledgments:}

We are thankful to the Tehran University of Medical Sciences and Occupational and Environmental Health Research Center at Shahroud University of Medical Sciences for partially funding this investigation. The authors also appreciate all supervisors and nurses in the educational hospitals affiliated with Tehran University of Medical Sciences who assisted in conducting this study. We are very grateful for their cooperation.

\section{Conflict of Interest:}

There is no conflict of interest to be declared.

Authors' contributions:

All authors contributed to this project and article equally. All authors read and approved the final manuscript. 


\section{References:}

1) Aiken LH, Clarke SP, Sloane DM. Hospital staffing, organization, and quality of care: cross-national findings. Int J Qual Health Care. 2002; 14(1): 5-13. doi: 10.1093/intqhc/14.1.5 5-14, PMID: 11871630.

2) Letvak S, Ruhm CJ, McCoy T. Depression in hospital employed nurses. Clin Nurse Spec. 2012; 26(3): 177-82. doi: 10.1097/NUR.0b013e3182503ef0, PMID: 22504476.

3) Sveinsdottir H, Biering P, Ramel A. Occupational stress, job satisfaction, and working environment among Icelandic nurses: a cross-sectional questionnaire survey. Int J Nurs Stud. 2006; 43(7): 875-89. doi: 10.1016/j.ijnurstu.2005.11.002, PMID: 16360157.

4) Letvak SA, Ruhm CJ, Gupta SN. Nurses' presenteeism and its effects on self-reported quality of care and costs AJN. Am J Nurs. 2012; 112(2): 30-8. doi: 10.1097/01.NAJ.0000411176.15696.f9, PMID: 22261652.

5) Anderson DJ, Webster CS. A systems approach to the reduction of medication error on the hospital ward. J Adv Nurs. 2001; 35(1): 34-41. doi: 10.1046/j.1365-2648.2001.01820.x, PMID: 11442680.

6) Nguyen HT, Nguyen TD, van den Heuvel ER, Haaijer-Ruskamp FM, Taxis K. Medication Errors in Vietnamese Hospitals: Prevalence, Potential Outcome and Associated Factors. PLoS One. 2015; 18; 10(9). doi: 10.1371/journal.pone.0138284, PMID: 26383873.

7) Hevia A, Hobgood C. Medical error during residency: to tell or not to tell. Ann Emerg Med. 2003; 42: 56570. doi: 10.1067/S0196-0644(03)00399-8, PMID: 14520327.

8) Crigger NJ. Always having to say you're sorry: an ethical response to making mistakes in professional practice. J Nurs Ethics. 2004; 11(6): 568-76. doi: 10.1191/0969733004ne739oa, PMID: 15597937.

9) Tang FI, Sheu SJ, Yu S, Wei IL, Chen CH. Nurses relate the contributing factors involved in medication errors. J Clin Nurs. 2007; 6(3): 447-57. doi: 10.1111/j.1365-2702.2005.01540.x, PMID: 17335520.

10) Webster CS, Anderson DJ. A practical guide to the implementation of an effective incident reporting scheme to reduce medication error on the hospital ward. Int J Nurs Pract. 2002; 8(4): 176-83. doi: 10.1046/j.1440-172X.2002.00368.x, PMID: 12100674.

11) Airila A, Hakanen J, Punakallio A, Lusa S, Luukkonen R. Is work engagement related to work ability beyond working conditions and lifestyle factors? Int Arch Occup Environ Health. 2012; 85(8): 915-25. doi: 10.1007/s00420-012-0732-1, PMID: 22270385.

12) Wakefield DS, Wakefield BJ, Borders T, Uden-Holman T, Blegen M, Vaughn T. Understanding and comparing differences in reported medication administration error rates. Am J Med Qual. 1999; 14(2): 7380. doi: 10.1177/106286069901400202, PMID: 10446668.

13) El Fassi M, Bocquet V, Majery N, Lair ML, Couffignal S, Mairiaux P. Work ability assessment in a worker population: comparison and determinants of Work Ability Index and Work Ability score. BMC Public Health. 2013; 13: 305. doi: 10.1186/1471-2458-13-305, PMID: 23565883.

14) Tuomi K, Huuhtanen P, Nykyri E, Ilmarinen J. Promotion of work ability, the quality of work and retirement. Occup Med (Lond). 2001; 51: 318-24. doi: 10.1093/occmed/51.5.318, PMID: 11473138.

15) Broadbent DE, Cooper PF, FitzGerald P, Parkes KR. The Cognitive Failures Questionnaire (CFQ) and its correlates. Br J Clin Psychol. 1982; 21(1): 1-16. doi: 10.1111/j.2044-8260.1982.tb01421.x, PMID: 7126941.

16) Benavides FG. Ill health, social protection, labour relations, and sickness absence. Occup Environ Med. 2006; 63(4): 228-9. doi: 10.1136/oem.2005.025817, PMID: 16556740.

17) Scand J. Improving work ability in construction workers-lets get to work. Work Environ Health. 2009; 35(5): 321-324. doi: 10.5271/sjweh.1345, PMID: 19696954.

18) Hengel K, Joling K, Proper K, Blatter B, Bongers P. A worksite prevention program for construction workers: design of a randomized controlled trial. BMC Public Health. 2010; 10: 336. doi: 10.1186/14712458-10-336, PMID: 20546568, PMCID: PMC2896359.

19) Ahlstrom L, Grimby-Ekman A, Hagberg M, Dellve L. The work ability index and single-item question: associations with sick leave, symptoms, and health - a prospective study of women on long-term sick leave. Scand J Work Environ Health. 2010; 36(5): 404-12. doi:10.5271/sjweh.2917, PMID: 20372766.

20) Knezevic B, Milosevic M, Golubic R, Belosevic L, Russo A, Mustajbegovic J. Work-related stress and work ability among Croatian university hospital midwives. Midwifery. 2011; 27(2): 146-53. doi: 10.1016/j.midw.2009.04.002, PMID: 19589631.

21) Bartram T, Joiner TA, Stanton P. Factors affecting the job stress and job satisfaction of Australian nurses: implications for recruitment and retention. Contemp Nurse. 2004; 17(3): 293-304. doi: 10.5172/conu.17.3.293, PMID: 15551680. 
22) Farsi Z, Dehghan-Nayeri N, Negarandeh R, Broomand S. Nursing profession in Iran: An overview of opportunities and challenge. Jap J Nur Sci. 2010; 7: 9-18, doi: 10.1111/j.1742-7924.2010.00137.x, PMID: 20618672.

23) Arastoo AA, Montazeri A, Abdolalizadeh M, Ghasemzadeh R, Ahmadi, Azizi A, Psychometric properties of Persian version of the Work Ability Index questionnaire. Payesh. 2013; 12: 535-43.

24) Allahyari T, Saraji GN, Ad J, Hosseini M, Iravani M, Younesian M, Kass SJ. Cognitive failures, driving errors and driving accidents. Int $J$ Occup Saf Ergon. 2008; 14(2): 149-58. doi: 10.1080/10803548.2008.11076759, PMID: 18534151.

25) Stenfors CUD, Hanson LM, Oxenstierna G, Theorell T, Nilsson G. Psychosocial Working Conditions and Cognitive Complaints among Swedish Employees. PLoS ONE. 2013; 8(4): e60637. doi: 10.1371/journal.pone.0060637, PMID: 23560101.

26) Ilmarinen JE. Aging workers. Occup Environ Med. 2001; 58(8): 546-52. doi: 10.1136/oem.58.8.546, PMID: 11452053, PMCID: PMC1740170.

27) Chiang HY, Lin SY, Hsu SC, Ma SC. Factors determining hospital nurses' failures in reporting medication errors in Taiwan. Nurs Outlook. 2010; 58(1): 17-25. doi: 10.1016/j.outlook.2009.06.001, PMID: 20113751.

28) Van den berg T, Alavinia SM, Bredt FJ, Lindeboom D, Elders LA, Burdorf A. The influence of psychosocial factor at work and life style on health and work ability among professional workers. Int Arch Occup Environ Health. 2008; 81(8): 1029-936. doi: 10.1007/s00420-007-0296-7, PMID: 18175140.

29) Rossetti AC, Gaidzinski RR, Bracco MM. Determining workload and size of nursing team in the pediatric emergency department. Einstein (Sao Paulo). 2014; 12(2): 217-22. doi: 10.1590/S1679-45082014AO2945, PMID: 25003929.

30) Portela LF, Rotenberg L, Pereira Almeida AL, Landsbergis P, Griep RH. The Influence of Domestic Overload on the Association between Job Strain and Ambulatory Blood Pressure among Female Nursing Workers. Int J Environ Res Public Health. 2013; 10(12): 6397-9408. doi: 10.3390/ijerph10126397. PMID: 24287860, PMCID: PMC3881121.

31) Johnstone PL. Occupational stress in the operating theatre suite: Should employers be concerned? Aust Health Rev. 2004; 32(1): 60-80. doi: 10.1071/AH990060, PMID: 10387906.

32) Lund T, Iversen L, Poulsen KB. Work environment factors, health, lifestyle and marital status as predictors of job change and early retirement in physically heavy occupations. Am J Ind Med. 2001; 40(2): 161-9. doi: 10.1002/ajim.1084, PMID: 11494344.

33) Martinez MC, Latorre MRDO, Fischer FM. Validity and reliability of the Brazilian version of the Work ability index questionnaire. Revista de Saúde Publica. 2009; 43(3): 525-32. doi: 10.1590/S003489102009005000017, PMID: 19347177.

34) Camerino D, Conway PM, Van der Heijden BIJM, Estryn-Behar M, Consonni D, Gould D, et al. Lowperceived work ability, ageing and intention to leave nursing: a comparison among 10 European countries. J Adv Nurs. 2006; 56(5): 542-52. doi: 10.1111/j.1365-2648.2006.04046.x, PMID: 17078829.

35) Zwart BC, Frings-Dresen MH, van Duivenbooden JC. Test-retest reliability of the Work Ability Index questionnaire. Occup Med (Lond). 2002; 52(4): 177-81. doi: 10.1093/occmed/52.4.177, PMID: 12091582. 